\title{
Impact of Fixed-Dose Combinations of Antiretrovirals on Prevalence Trends of HIV Resistance: A 7 Year Follow-Up Study
}

Angeles Jaen ${ }^{1 *}$, Elisabeth Buira ${ }^{2}$, Albert Giménez ${ }^{2}$, Tomás Pumarola ${ }^{3}$, Teresa Puig ${ }^{4}$, Jordi Niubó ${ }^{5}$, Mariona Xercavins ${ }^{6}$, Daniel Podzamczer ${ }^{5}$, Bonaventura Clotet ${ }^{4}$, Josep Maria Gatell ${ }^{3}$ and David Dalmau ${ }^{1,7}$ On Behalf of CHRN Group Study

${ }^{1}$ Fundació Docència i Recerca Mútua Terrassa, Catalonia, Spain

${ }^{2}$ Direcció General de Salut Pública, Barcelona, Catalonia Government, Spain

${ }^{3}$ Hospital Clinic-IDIBAPS de Barcelona, Catalonia, Spain

${ }^{4}$ IrsiCaixa, Hospital Universitari Germans Trias i Pujol, Badalona, Catalonia, Spain

${ }^{5}$ Hospital Universitari de Bellvitge-IDIBELL, Hospitalet, Catalonia, Spain

${ }^{6}$ Catlab, Catalonia, Spain

${ }^{7}$ Hospital Universitari MutuaTerrassa, University of Barcelona, Catalonia, Spain

\begin{abstract}
Objectives: To determine the effectiveness of the introduction of fixed-dose combinations of antiretrovirals (FDCAs) in reducing resistance, and to describe trends of resistance-associated mutations (RAMs) in relation to drug exposure and the risk factors associated with multi-class drug resistance (MCDR) in Catalonia (Spain).

Methods: Observational prospective study of HIV Resistance in Catalonia from 2002 to 2008. We included $2,718 \mathrm{HIV}+$ patients $(\geq 16$ years of age) with virological failure (Viral Load $>1000$ copies $/ \mathrm{ml}$ ). Differences between the Pre-FDCAs period (2002-2005) and the Post-FDCAs period (2005-2008) were assessed by multivariate logistic regressions. Prevalence of resistances and exposure to ARVs. trends were also assessed by test of trend

Results: We observed a downward trend from 2002 to 2008 in all class-resistance mutations and RAMS $(\mathrm{p}<0.0001)$. This trend coincides with a reduction in exposure to older ARVs., and with an increase in exposure to newer drugs. Multivariate analyses showed the Post-FDCAs period as an independent protective factor for the presence of any resistance, for MCDR, and for major mutations of reverse transcriptase and protease, with Odds Ratios $(95 \% \mathrm{Cl})$ between $0.32(0.26-0.39)$ and $0.67(0.51-0.86)$. Male sex, sexual transmission group, older age, duration of HIV infection, number of treatment failures and exposure to three-class drugs are also risk factors for the presence of MCDR.
\end{abstract}

Conclusions: There was an important reduction of the risk of class-resistances, MCDR and RAMs in the PostFDCAs period independently of others factors. Reductions in specific mutations are related to changes in antiretroviral use. These results support the use of FDCAs for the treatment of HIV infection.

Keywords: Antiretroviral therapy; HIV drug resistance; Fixeddose combination of antiretrovirals; Genotypic mutations; Prevalence; Multiple drug resistance; Resistance-associated mutation trend; HIV resistance risk factors

\section{Introduction}

The efficacy of antiretroviral (ARV) therapy has significantly improved the survival and quality of life of HIV infected subjects [1]. The development of simplified treatment guidelines and new drugs with higher efficacy, better tolerability and fewer adverse effects has improved treatment compliance $[2,3]$. In this context, the emergence of treatment resistance is the greatest challenge to achieve maximum effectiveness in countries with access to antiretroviral therapy. HIV drug resistance is associated with virological failure and clinical HIV progression, limiting subsequent therapy options [4-6]. The clinical utility and cost-effectiveness of genotypic antiretroviral resistance testing following antiretroviral failure has been demonstrated in clinical practice [7]. Current European and International guidelines recommend drug resistance testing [8,9]. Prevalence of acquired resistance to at least one drug varied from $76 \%$ to $83 \%$ in countries with long history of exposure to ARV therapy. However, the reported prevalence of drug-class resistance and associated mutations among treated HIV+ patients varies widely [1013]. Aside from differences in ARV exposure and study methodology, this variability could be the result of the different algorithms used for the clinical and epidemiological estimation of genotypic resistances [13-15].

Emergence of HIV drug resistance is a public health concern. The monitoring of the regional levels of HIV-1 resistance may facilitate the rational use of antiretroviral drugs. Although there are many studies of drug class resistance prevalence, fewer studies on drug resistanceassociated mutations (RAMs) trends in relation to antiretroviral exposure in specific geographical areas are available. In addition, it is important to take into account the calendar period when study results are considered. Recent publications show a decreasing trend or stabilization in the prevalence of resistance, probably due to the improvement in treatment options [10,16-18]. However, most of them are not representative of the HIV+ population, or do not have information on treatment exposure. Although there is strong evidence of the efficacy and higher treatment adherence of fixed-dose combinations of ARVs. (FDCAs) [19,20], there is scarce epidemiological information on the impact of new drugs or FDCAs on ARVs. resistance at HIV+ population level. Knowledge on the risk factors implicated in ARVs. resistance is essential to prevent resistance and to optimise treatment. On the other hand, the critical current economical situation has led the

*Corresponding author: Ángeles Jaen, Fundació Docència i Recerca Mutua Terrassa C/ Sant Antoni nº 1908221 Terrassa -Barcelona, Spain, Tel: +34 937365050 ext. 3929; Fax: +34 9373670 11; E-mail: ajaen@mutuaterrassa.es

Received November 26, 2014; Accepted January 05, 2015; Published January 15, 2015

Citation: Jaen A, Buira E, Giménez A, Pumarola T, Puig T, et al. (2015) Impact of Fixed-Dose Combinations of Antiretrovirals on Prevalence Trends of HIV Resistance: A 7 Year Follow-Up Study. J AIDS Clin Res 6: 416. doi:10.4172/2155 6113.1000416

Copyright: ( 2015 Jaen A, et al. This is an open-access article distributed unde the terms of the Creative Commons Attribution License, which permits unrestricted use, distribution, and reproduction in any medium, provided the original author and source are credited. 
Government to consider the withdrawal of the fixed-dose combinations of antiretrovirals (FDCAs) in our country [19]. Epidemiological data on their efficacy will assist in reaching the right decision.

Previous clinical studies have reported that the prevalence of genotypic resistance among subjects with treatment failure in Spain is between 72\%-79\% [21,22] (71\%-77\% for Nucleoside reverse transcriptase inhibitors (NRTIs), 53\% for Protease inhibitors (PI), 53\%-42\% for Nonnucleoside reverse transcriptase inhibitors (NNRTIs)). However, these data were restricted to specific clinical settings, were conducted on a limited number of samples and included retrospective data.

In 2002, the Catalan Health Service (CatSalut) initiated a project monitoring HIV genotypic resistance to ARVs. in Catalonia (Spain). This project provides epidemiological, clinical, and treatment information and monitors resistance patterns over time in all HIV + patients living in Catalonia. Using this information, the aims of this study are: 1- to determine the effectiveness of the new FDCAS and their effect on genotypical resistances in patients failing antiretroviral treatment; 2 - to describe the epidemiological trends of class-resistance and resistanceassociated mutation (RAMs) patterns, and their association with drug exposure; 3- to identify risk factors associated with Multi-class drug resistance (MCDR) in HIV+ treated patients-. This Knowledge may help to prevent resistances through better treatment management and to take political decisions based on scientific evidence.

\section{Methods}

\section{Ethics statement}

We followed the data protection directives according to current law (LOPD 15/1999) and the data are completely anonymised. This study has been authorised by the Department of Health of the Catalan Government.

The Catalonia HIV Resistance Network (CHRN) is a centralized database that contains prospective data of all genotypic tests performed since 2002 on all HIV+ patients attending Catalan Health Services. The present study is an observational prospective cohort study.

\section{Inclusion criteria}

Pre-treated HIV infected patients older than 16 years of age with treatment failure (defined as virological failure $>1000$ copies/ml of HIV_1 RNA) that were tested at least once from January 2002 to June 2008.

\section{Variables}

A data set including demographic, country of origin, transmission group, date of HIV diagnosis, clinical data, and ARVs. treatment history was created using the Access programme. ARVs. test results including specific genotypic mutations and their resistance interpretation were also included.

\section{Laboratory techniques and genotyping}

All samples were analysed by expert technicians in four referral centres. RNA extraction and sequencing were performed using the TRUGENE ${ }^{\mathrm{m}}$ Visible Genetics HIV-1 Genotyping Kit and the Applied Biosystems ViroSeq HIV-1 Genotyping System following the manufacturer's instructions.

\section{Genotypic resistance}

Susceptibility to ARVs. was defined according to three categories: Resistant (R), Partially Resistant or Intermediate (I) and Sensitive (S). Partially Resistant or I was defined as having some degree of resistance to any specific ARV drug. We describe the genotypic resistance for each of the following ARVs.: Nucleoside reverse transcriptase inhibitors (NRTIs), including Zidovudine (AZT), Didadosine (ddI), Zalcitabine (ddC), Estavudine (d4T), Lamivudine (3TC), Abacavir (ABC), Tenofovir (TDF) and Emtricitabine (FTC); Non-nucleoside reverse transcriptase inhibitors (NNRTIs), including Nevirapine (NVP) and Efavirenz (EFV); and Protease Inhibitors (PI), including Indinavir (IDV), Saquinavir (SQV), Nelfinavir (NFV), Amprenavir (APV), Lopinavir/ritonavir (LPV/RTV), Tipranavir (TPV), Atazanavir (ATV), and Fosamprenavir (Fos APV). Resistance to Ritonavir was not considered as this drug is administered to boost other protease inhibitors. "Two-class drugresistance" was defined as resistance to at least one drug from two different classes. "Multi-class drug-resistance" (MCDR) was considered in those patients with "Three -class drug resistance", defined as resistance to at least one drug from each of the three classes.

\section{FDCAs period}

We defined the variable "FDCAs period" based on the introduction of fixed-dose combinations of antiretrovirals (FDCAs) in our country in the second half of 2005. The FDCAs referred to were ABC plus 3TC, and TDF plus FTC that were introduced in 2005, but not AZT plus 3TC, nor AZT plus 3TC plus Abacavir that were introduced previously. In addition, we considered in post FDCAs period new boosted PI therapy (above all fosamprenavir and atazanavir plus ritonavir), but not Lopinavir plus Ritonavir that was introduced in 2002. "Pre FDCAs period" patients had their genotypic test performed from January 2002 to June 2005, and "Post FDCAs period" patients had their tests performed between July 2005 to June 2008 .

\section{Statistical analyses}

For the purposes of this study, we used the results of the first resistance test performed in each patient. Resistance to ARVs. was analysed as a binary outcome: Resistant (if tests results were R or I) or Sensitive (S). Mutations were analysed according the IAS-USA guidelines (2008) [23] and the RIS algorithm (AIDS Rev 2008) [15]. Statistical analyses were conducted using the statistical package Stata version SE/9 (Stata Corporation, Texas, USA). The Mann Whitney U-test and Pearson Chisquare test were used to investigate the association of Resistance and RAMS with FDCAs period and other variables. Resistance analysis over time was performed using Mantel's Chi-square test for trend and logistic regressions. Multivariate analyses were performed to assess associated factors to any major resistance mutation of NRTI/NNRTI/PI, to any resistance, and to MCDR, focusing on the FDCAs period. Treatment exposure was considered as exposure to one ARV class, two drugclasses, or three drug-classes. All single ARVs. were included in the analysis models for specific resistance mutations as appropriate. Other co-variables included in the models were: sex, age, country of origin, transmission group (TG), prior AIDS, value of CD4 and Viral Load (VL) closer to date when the genotypic test was performed, number of treatment failures, time since HIV+ diagnosis, referral laboratory centre, and type of test. A p value $<0.05$ (or a $95 \%$ CI that does not include the unit) was considered statistically significant.

\section{Results}

No genetic amplification was obtained in 270 (7.7\%) of the 3,495 patients analysed, leaving 3,225 samples with resistance data. However, we restricted the analysis to the 2,718 patients that had antiretroviral treatment information available. The clinical and epidemiological characteristics of the population and results about genotypic classresistances by FDCAs period are described in Table 1 . The median age was 40.4 years (IQR: $36.5-45.0$ ), and a total of 1,981 participants (72.9\%) were male. The median CD4 count was 298 cells/ $\mu$ (IQR: 162- 
Citation: Jaen A, Buira E, Giménez A, Pumarola T, Puig T, et al. (2015) Impact of Fixed-Dose Combinations of Antiretrovirals on Prevalence Trends of HIV Resistance: A 7 Year Follow-Up Study. J AIDS Clin Res 6: 416. doi:10.4172/2155-6113.1000416

471), and the median log10 HIV viral load was 4.2 copies/ml (IQR: 3.64.8). No differences were found in gender, TG, country of origin, and AIDS fulfilled criteria between Pre and Post FDCAs patients. We found differences in the median age between groups. Regarding exposure to ARV, there was lower exposure to Three-class ARVs. (46.1\% vs. $60.2 \%$; $\mathrm{p}<0.001)$ and higher to Two-class ARVs. $(47.9 \% 35.4 \%$; $<<0.001)$ in the Post FDCAs group compared to the Pre FDCAs group. In addition, there were more patients with one treatment failure $(23.7 \%$ vs. $17.2 \%)$ in the Post FDCAs group. We observed differences in prevalence of resistances between the Post and Pre FDCAs period for any-class (63.7\% vs. $84.0 \%)$, two-class $(44.2 \%$ vs. $65.0 \%)$ and multi-class drug resistance $(9.5 \%$ vs. $21.4 \%)$; $(\mathrm{p}<0.0001)$. In addition, we observed differences by FDCAs period for NRTIs ( $54.4 \%$ vs. $77.0 \%$ ), NNRTIs (40.9\% vs. $56.2 \%)$ and PIs (16.1\% vs. $16.122 .1 \%)$ genotypic resistances; $(\mathrm{p}<0.0001)$ (Table 1).
Differences in prevalence of related mutations for NRTIs, NNRTIs and PIs by FDCAs period are shown in Table 2. A significant decrease in the prevalence of all class-RAM was observed in the Post FDCAs period ( $\mathrm{p}$ value between 0.05 and $<0.0001$ ).

Prevalence trends of genotypic class-resistance during the period of study are shown in Figure 1. Genotypic class-resistance dropped from $83.3 \%$ to $41.3 \%$ in patients exposed to NRTIs, from $57.9 \%$ to $31.3 \%$ in patients exposed to NNRTIs, and from $47.6 \%$ to $17.3 \%$ in those exposed to PIs $(\mathrm{p}<0.0001)$. Additionally, Multi-class drug resistance decreased over time $(31.8 \%$ to $7.3 \%$; $\mathrm{P}<0.0001)$.

\section{NRTIs exposure and prevalence trends of related mutations}

These results are included in Figures 2a to 2d, that show the results of trend analyses on ARVs. exposure and related mutations in patients

\begin{tabular}{|c|c|c|c|c|}
\hline & \multirow{2}{*}{$\begin{array}{c}\text { TOTAL } \\
\mathrm{N}=2718(\%)\end{array}$} & \multicolumn{2}{|c|}{ FDCAs period ${ }^{a}$} & \multirow[b]{2}{*}{$P$ value $^{\mathrm{b}}$} \\
\hline & & $\begin{array}{c}\text { Pre FDCAs }{ }^{\mathrm{a}} \\
\mathrm{N}=1,654(60.8 \%)\end{array}$ & $\begin{array}{c}\text { Post FDCAsa } \\
N=1,064(39,2 \%)\end{array}$ & \\
\hline Age (years) & $40.4(36.5-45.0)^{c}$ & $39.8(36.5-44.4)^{c}$ & $41.2(36.7-45.8)^{c}$ & $<0.001$ \\
\hline $\begin{array}{l}\text { Age category } \\
\leq 35 \text { years } \\
35-55 \text { years } \\
\geq 55 \text { years }\end{array}$ & $\begin{array}{c}605(22.3) \\
1,947(71.6) \\
166(6.1)\end{array}$ & $\begin{array}{c}375(22.7) \\
1,184(71.6) \\
95(5.7)\end{array}$ & $\begin{array}{l}230(21.6) \\
763(71.7) \\
71(6.7)\end{array}$ & ns \\
\hline $\begin{array}{l}\text { Gender } \\
\text { Men } \\
\text { Women }\end{array}$ & $\begin{array}{c}1,981(72.9) \\
737(27.1)\end{array}$ & $\begin{array}{c}1,227(74.2) \\
427(25.8)\end{array}$ & $\begin{array}{l}754(70.9) \\
366(29.1)\end{array}$ & 0.06 \\
\hline $\begin{array}{l}\text { Transmission group } \\
\text { IDU }^{d} \\
\text { Heterosexual } \\
\text { Men have sex with men }\end{array}$ & $\begin{array}{l}1,058(38.9) \\
772(28.4) \\
542(19.9)\end{array}$ & $\begin{array}{l}668(40.4) \\
465(28.1) \\
339(20.5)\end{array}$ & $\begin{array}{l}390(36.6)^{\mathrm{e}: 0.06} \\
307(28.9)^{\mathrm{e}: n s} \\
203(19.1)^{\mathrm{e}: \mathrm{ns}}\end{array}$ & ns \\
\hline $\begin{array}{l}\text { Country of origin } \\
\text { Spain } \\
\text { Others }\end{array}$ & $\begin{array}{c}2,568(94.5) \\
150(5.5)\end{array}$ & $\begin{array}{c}1,572(95.0) \\
82(4.8)\end{array}$ & $\begin{array}{l}996(93.6) \\
68(6.4)\end{array}$ & 0.1 \\
\hline AIDS & $990(36.4)$ & $615(37.2)$ & $375(35.2)$ & ns \\
\hline CD4 (cells/ $\mu l)$ & $298(162-471)^{c}$ & $300(166-470)^{c}$ & $290(155.473 .2)^{\mathrm{c}}$ & ns \\
\hline log10 HIV-1 RNA (copies/ml) & $4.2(3.6-4.8)^{c}$ & $4.1(3.6-4.8)^{c}$ & $4.3(3.6-4.8)^{c}$ & ns \\
\hline Years since HIV+ diagnosis & $10.8(6.8-14.4)^{c}$ & $10.5(6.6-13.9)^{c}$ & $11.4(7.2-5.6)^{c}$ & 0.0001 \\
\hline $\begin{array}{l}\text { Class Drug Exposure: } \\
\text { One-class ARVs } \\
\text { Two-class ARVs } \\
\text { Three- class ARVs }\end{array}$ & $\begin{array}{c}138(5.1) \\
1,093(40.3) \\
1,484(54.7)\end{array}$ & $\begin{array}{c}74(4.5) \\
585(35.4) \\
995(60.2)\end{array}$ & $\begin{array}{c}64(6.0)^{\mathrm{e}: n s} \\
508(47.9)^{\mathrm{e}<0.0001} \\
489(46.1)^{\mathrm{e}<0.0001}\end{array}$ & $<0.0001$ \\
\hline $\begin{array}{l}\text { Number of treatment failures } \\
\text { One failure } \\
\text { Two failures } \\
\text { Three or more failures }\end{array}$ & $\begin{array}{l}536(19.7) \\
616(22.7) \\
1,566(57.6)\end{array}$ & $\begin{array}{l}284(17.2) \\
391(23.6) \\
979(59.2)\end{array}$ & $\begin{array}{c}252(23.7)^{\mathrm{e}<0.0001} \\
225(21.2)^{\mathrm{e}: n s} \\
587(55.2)^{\mathrm{e}^{: 0.04}}\end{array}$ & $<0.0001$ \\
\hline $\begin{array}{l}\text { Type of genotypic test } \\
\text { Trugene Visible Genetics } \\
\text { Applied Biosystems Viroseq }\end{array}$ & $\begin{array}{l}1,157(42.7) \\
1,552(57.3)\end{array}$ & $\begin{array}{l}760(45.2) \\
886(53.8)\end{array}$ & $\begin{array}{l}397(37.3) \\
666(62.6)\end{array}$ & $<0.0001$ \\
\hline $\begin{array}{l}\text { Drug- Class Resistance } \\
\text { Any-class drug resistance } \\
\text { Two- class drug resistance } \\
\text { Multiple-class }{ }^{f} \text { drug resistance }\end{array}$ & $\begin{array}{c}2,068(76.1) \\
1,545(56.8) \\
455(16.7)\end{array}$ & $\begin{array}{c}1,390(84.0) \\
1,075(65.0) \\
354(21.4)\end{array}$ & $\begin{array}{l}678(63.7) \\
470(44.2) \\
101(9.5)\end{array}$ & $\begin{array}{l}<0.0001 \\
<0.0001 \\
<0.0001\end{array}$ \\
\hline $\begin{array}{l}\text { GR } R^{g} \text { to } A R V s: \\
\text { NRTIs } \\
\text { NNRTIs } \\
\text { Pls }\end{array}$ & $\begin{array}{c}1,853(68.2) \\
1,365(50.2) \\
850(31.3)\end{array}$ & $\begin{array}{l}1,274(77.0) \\
930(56.2) \\
615(22.1)\end{array}$ & $\begin{array}{l}579(54.4) \\
435(40.9) \\
235(16.1)\end{array}$ & $\begin{array}{l}<0.0001 \\
<0.0001 \\
<0.0001\end{array}$ \\
\hline
\end{tabular}

a FDCAs period: Pre FDCAs: patients with genotypical resistance test made from January 2002 to June 2005; Post FDCAs patients with genotypical resistance test made from July 2005 to June 2008

${ }^{\mathrm{b}} \mathrm{p}$ value from chi-square test for qualitative variables, or Mann-Whitney $\mathrm{U}$ test for quantitative variables

c Median and Interquartil range (IQR)

${ }^{d}$ Intravenous drug users

e $\mathrm{P}$ value from Z-test for proportions- Independent groups; ns: no significant

${ }^{\mathrm{f}}$ Considered as three-class drugs resistance

genotipical Resistances

Table 1. Differences in characteristic and genotypic resistances (GR) data among infected HIV population with treatment failure in Catalonia by FDCAs period. 


\begin{tabular}{|l|c|c|c|c|}
\hline & $\begin{array}{c}\text { Pre FDCAs }^{\mathrm{a}} \\
\mathrm{N}=1,654(\%)\end{array}$ & $\begin{array}{c}\text { Post FDCAs } \\
\mathrm{N}=1,064(\%)\end{array}$ & $\mathrm{p}^{\mathrm{b}}$ & $\begin{array}{c}\text { TOTAL } \\
\mathrm{N}=2,718(\%)\end{array}$ \\
\hline Reverse transcriptasa & \multicolumn{5}{|l|}{} \\
\hline M184V/I & $823(49.8)$ & $433(40.7)$ & $<0.0001$ & $1,256(46.2)$ \\
\hline T215Y/F & $675(40.8)$ & $268(25.2)$ & $<0.0001$ & $943(34.7)$ \\
\hline M41L & $572(34.6)$ & $212(19.9)$ & $<0.0001$ & $784(28.8)$ \\
\hline D67N & $421(25.5)$ & $167(15.7)$ & $<0.0001$ & $588(21.6)$ \\
\hline L210W & $393(23.8)$ & $146(13.7)$ & $<0.0001$ & $539(19.8)$ \\
\hline K70R & $291(17.6)$ & $136(12.8)$ & 0.001 & $427(15.7)$ \\
\hline K219Q/E & $274(16.6)$ & $138(13.0)$ & 0.01 & $412(15.2)$ \\
\hline L74V & $180(10.9)$ & $67(6.4)$ & $<0.0001$ & $247(9.2)$ \\
\hline K65R & $119(7.2)$ & $52(4.9)$ & 0.01 & $171(6.3)$ \\
\hline TAMS & $915(55.3)$ & $367(34.5)$ & $<0.0001$ & $1,282(47.2)$ \\
\hline K103N & $512(31.0)$ & $245(23.0)$ & $<0.0001$ & $773(27.9)$ \\
\hline V108I & $387(23.4)$ & $183(17.2)$ & $<0.0001$ & $570(21.0)$ \\
\hline Y181C/I & $288(17.4)$ & $106(10.0)$ & $<0.0001$ & $394(14.5)$ \\
\hline G190A/S & $155(9.4)$ & $46(4.3)$ & $<0.0001$ & $201(7.4)$ \\
\hline Protease & & & & \\
\hline L90M & $337(20.4)$ & $126(11.8)$ & $<0.0001$ & $463(17.0)$ \\
\hline M46I/L & $302(18.3)$ & $131(12.3)$ & $<0.0001$ & $433(15.9)$ \\
\hline V82A/F/T/S & $269(16.3)$ & $98(9.2)$ & $<0.0001$ & $367(13.5)$ \\
\hline I84V & $123(7.4)$ & $59(5.5)$ & 0.05 & $182(6.7)$ \\
\hline
\end{tabular}

a FDCAs period: Pre FDCAs: patients with genotypical resistance test made from January 2002 to June 2005; Post FDCAs patients with genotypical resistance test made from July 2005 to June 2008.

b $p$ value from chi-square test

cTAMS: Thymidine analog mutations: T215F/Y, M41L, D67N, L210W, K70R, K219Q/E

Table 2: Prevalence of the most frequently resistance associated mutations among $\mathrm{HIV}+$ adult patients with virological failure in Catalonia by FDCAs Period.

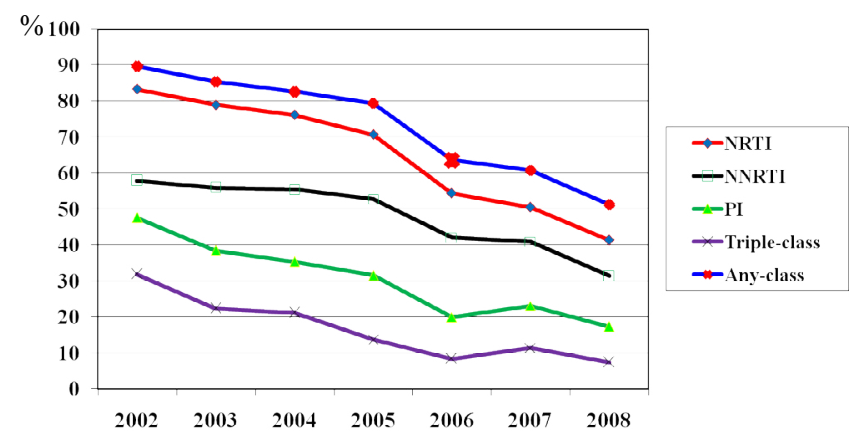

Figure 1 Prevalence of genotypic class-resistance among adult HIV+ patients exposed to ARVs with treatment failure.

with one or more treatment failures.

We observed a declining trend of exposure to the following ARVs. during the period studied (from 2002 to 2008): Abacavir (alone or in combination with other ARVs.; $\mathrm{p}=0.01)$, ddI, and $\mathrm{d} 4 \mathrm{~T}(\mathrm{p}<0.0001)$. However, AZT exposure (alone or in combinations with other ARVs.) decreased in 2008 although no significant trend was found. TAMS prevalence also had a declining trend during the period of study $(p<0.0001)$ (Figure 2a). On the other hand, the use of Emtricitabine (FTC), which was introduced in 2005 , increased to $26 \%$ by 2008 , while the 3TC exposure decreased $(\mathrm{p}<0.0001)$, and the related M184V mutation prevalence decreased during the same period $(\mathrm{p}<0.0001)$ (Figure 2b). Exposure to the combination of TDF and ddI experienced a sharp increase until 2004, followed by a decrease afterwards $(\mathrm{p}<0.0001)$ (Figure 2c). The prevalence of the related K65R mutation followed the same trend $(\mathrm{p}<0.01)$ (Figure $2 \mathrm{c}$ ).

\section{NNRTIs exposure and prevalence trends of related mutations}

Among NNRTIs, we observed a declining trend in exposure to EFV from 2006 to 2008 ( $\mathrm{p}<0.01$ ), and exposure to NVP decreased from 2005 to 2007 , with a slight increase in $2008(\mathrm{p}<0.00001)$. Regarding related resistance mutations, we observed a decrease overtime for all RAMs $(\mathrm{p}<0.0001)$ except for G190A/S that remained stable (Figure 2d).

\section{PIs exposure and prevalence trends of related mutations}

Trends of eexposure to PI's are described in Figure 2e. Exposure to Indinavir, Nelfinavir, and Amprenavir decreased over time without not a single case in 2008 ( $\mathrm{p}<0.0001)$. Exposure to Saquinavir remained stable during study period ( $\mathrm{p}=0.3$ ). Exposure to TPV, FosAPV, and ATV (all started in 2005) increased $(\mathrm{p}<0.001)$, although the proportion of TPV was very low. Non significant trend was found for the exposure to Lopinavir/ritonavir. We found a declining trend for the most frequent mutations associated with PIs including L90M, M46I/L, and V82A/F/ $\mathrm{T} / \mathrm{S}(\mathrm{p}<0.0001)$, but not for I84V (Figure $2 \mathrm{~d}$ ).

\section{Multivariate analysis}

We performed multivariate analyses to find out class-resistance and RAMs trends over time, especially since 2005 , coinciding with Post FDCAs period. Co-variables and ARV treatment exposure were considered in the analyses. Adjusted Odds Ratios (OR; 95\% CI) for Post FDCAs compared with Pre FDCAs are shown in table 3. Multivariate analyses showed a decrease of $68 \%$ in the presence of any resistance and $66 \%$ in the presence of triple-class drug resistance during post

\begin{tabular}{|c|c|c|}
\hline & $\begin{array}{l}\text { OR (Post vs Pre } \\
\text { FDCAs) }^{c}\end{array}$ & $\begin{array}{c}\text { Confidence Interval } \\
95 \%\end{array}$ \\
\hline Any-class drug resistance & 0.32 & $0.26-0.39$ \\
\hline Two-class drug resistance & 0.44 & $0.36-0.53$ \\
\hline Multiple-class drug resistance ${ }^{d}$ & 0.34 & $0.25-0.45$ \\
\hline TAMS & 0.44 & $0.36-0.54$ \\
\hline $\mathrm{M} 184 \mathrm{I} / \mathrm{V}^{\mathrm{e}}$ & 0.58 & $0.49-0.68$ \\
\hline $\mathrm{L} 74 \mathrm{I} / \mathrm{V}^{\mathrm{e}}$ & 0.58 & $0.42-0.80$ \\
\hline K65R & 0.52 & $0.38-0.71$ \\
\hline $\mathrm{K} 103 \mathrm{~N}^{\mathrm{f}}$ & 0.53 & $0.46-0.62$ \\
\hline V108I & 0.60 & $0.49-0.73$ \\
\hline $\mathrm{Y} 181 \mathrm{C} / \mathrm{I}^{\mathrm{f}}$ & 0.50 & $0.40-0.63$ \\
\hline G190A/S ${ }^{f}$ & 0.34 & $0.25-0.48$ \\
\hline L90M $^{g}$ & 0.45 & $0.36-0.58$ \\
\hline $\mathrm{M} 46 \mathrm{I} / \mathrm{L}^{\mathrm{g}}$ & 0.67 & $0.51-0.86$ \\
\hline V82A/F/T/S 9 & 0.44 & $0.33-0.58$ \\
\hline $184 V^{g}$ & 0.49 & $0.34-0.71$ \\
\hline
\end{tabular}

a FDCAs period: Pre FDCAs: patients with genotypical resistance test made from January 2002 to June 2005; Post FDCAs patients with genotypical resistance test made from July 2005 to June 2008.

b Co-variables included in the analysis: sex, age, country of origin, transmission group, prior AIDS, CD4, VL, number of treatment failures, time since HIV+ diagnosis, type of genotypic test, laboratory centre and class drug exposure (oneclass, two. or three-class).

c Odds ratios in the final models of the Post versus Pre FDCAs introduction for the presence of each definition of resistance or genotypical mutation adjusted for all co-variables

${ }^{\mathrm{d}}$ Considered as triple-class drug resistance

$\mathrm{e}$ In addition of other co-variables, we included in the regression model the exposure to: azt, ddi, 3tc, d4t, tnf, abc, and ftc, as independent co-variables

${ }^{f}$ In addition of other co-variables, we included in the regression model the exposure to: efv and nvp, as independent co-variables.

9 In addition of other co-variables, we included in the regression model the exposure to: idv, rtv, sqv, nfv, apv, Ipv, tpv, atv and fosapv as independent co-variables,

Table 3: Association of Class Resistances and Resistance Associated Mutations with FDCAs Period ${ }^{a}$ in a multivariate logistic regression analysis ${ }^{b}$. 
2a.

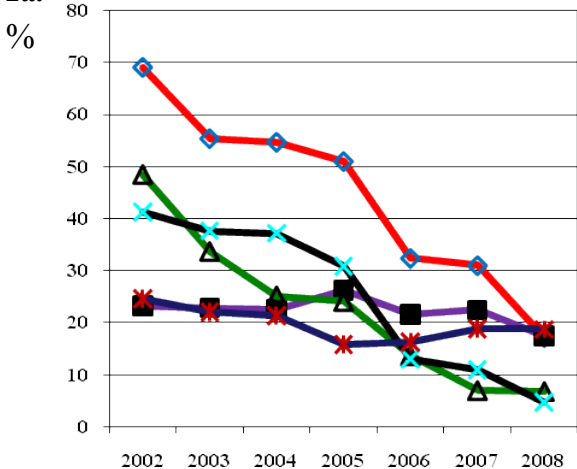

2b.

$\%$

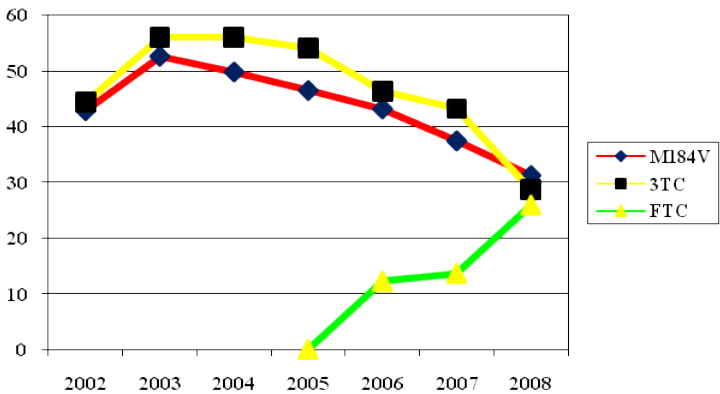

2e.

$\%$

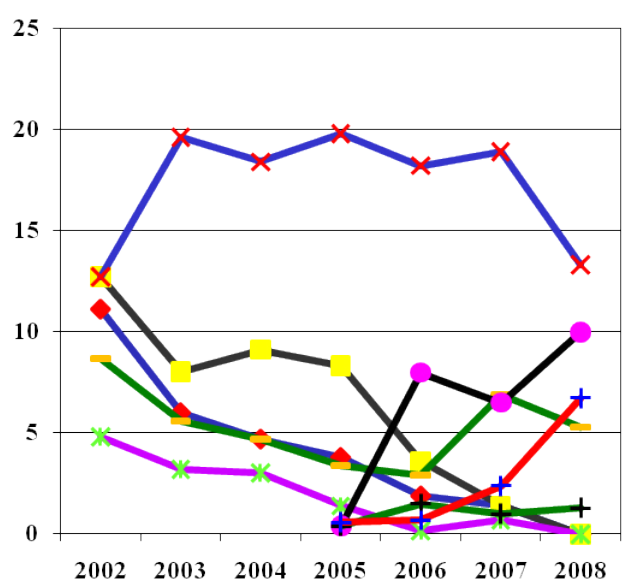

\begin{tabular}{ll|}
$\rightarrow \rightarrow$ Indinavir & -- Nelfinavir \\
$\rightarrow$ Lopinavir/Ritonavir & -- Saquinavir \\
$\rightarrow-$ Amprenavir & - Atazanavir \\
+ Tipranavir & + Fosamprenavir \\
\hline
\end{tabular}

$\%$ 2c.

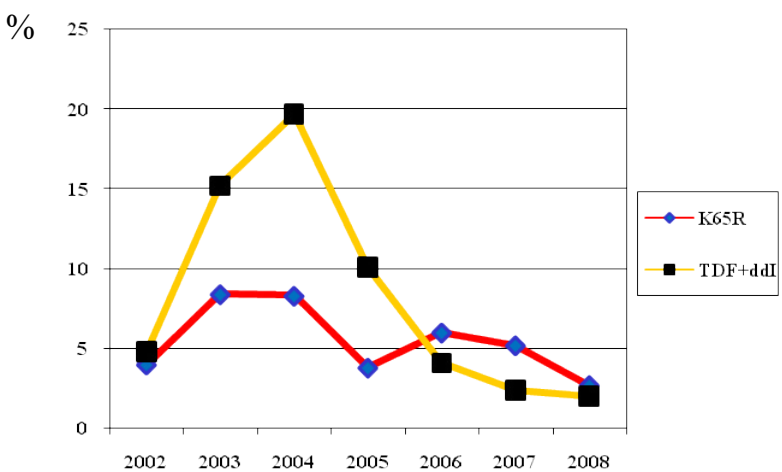

2d.

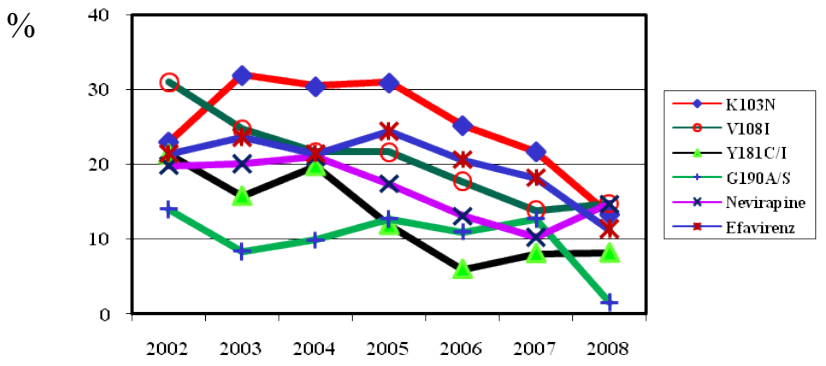

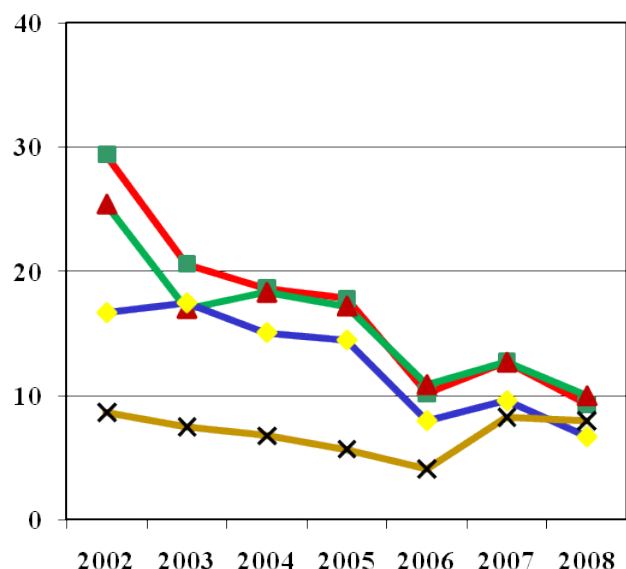

$2002 \quad 2003 \quad 2004 \quad 2005 \quad 2006 \quad 2007 \quad 2008$

$\rightarrow-\mathrm{L} 90 \mathrm{M} \rightarrow \mathrm{M} 46 \mathrm{I} / \mathrm{L} \quad--\mathrm{V} 82 \mathrm{~A} / \mathrm{F} / \mathrm{T} / \mathrm{S} \quad x-\mathrm{I} 84 \mathrm{~V}$

Figure 2 (a, b, c, $\mathbf{d}$ \&e): Trends of specific mutations and exposure to ARV's among adult HIV+ patients with treatment failure.

Figure 2a. Exposure to $A Z T^{\star}$ (azt; azt+3TC; azt+3TC+ABC), d4T, ddl, abacavir** $(A B C ; A B C+3 T C)$ and prevalence of TAMs mutations.

Figure 2b. Exposure to 3TC, FTC and prevalence of M184V mutation

Figure 2c. Exposure to TDF+ddl and prevalence of K65R mutation

Figure 2d. Exposure to nevirapine and efavirenz and prevalence of K103N, V108I, Y181C/l and G190A mutations

Figure 2e. Exposure to PIs and prevalence of L90M, M46I/L, V82A/F/T/S and I84V mutations. 
FDCAs period after adjusting for ARVs. exposure. In addition, we observed a decrease (from 33\% to 66\%) in the most frequent mutations related to NRTI, NNRTI and PI therapies. We found lower risk for any resistance, two-class resistance, triple-class resistance, and major resistance mutations in the Post FDCAs period, with OR between 0.32 ; 0.26-0.39 and 0.67; 0.51-0.86 (table 3). Other independent risk factors for Multi-class resistance were (OR; 95\%CI): male sex $(1.4 ; 1.02-1.9)$; age $\geq 55$ years vs. $\leq 35$ years $(2.1 ; 1.2-3.5)$; heterosexual $(1.8 ; 1.3-2.4)$ and men who have sex with men (1.9;1.4-2.6) compared with IDU TG; 2 or more treatment failures compared with one treatment failure $(1.8 ; 1.1$ 2.8), exposure to three-class ARVs. Compared with exposure to oneclass $(7.7 ; 2.8-21.5)$ and years since HIV+ diagnosis (1.07;1.04-1.10) (supplementary Table).

\section{Discussion}

To our knowledge this is the first HIV+ population based study that shows the impact of FDCAs on ARV resistances in our country, and describes the prevalence and trends of HIV drug-resistance in patients with virological failure receiving ART from the years 2002 to 2008. The main strength of our study is that all adult HIV + patients with virological failure within a geographical area (Catalonia) were included. In addition, we have information on treatment history, immune and virological information as well as epidemiological and socio-demographic data.

The prevalence of ARV class resistance, multi-class resistance, and RAMs dropped significantly in the Post-FDCAs period compared with the Pre-FDCAs period after adjusting for potential confounders and treatment exposure. Moreover, the higher decrease in ARV classresistance and MCDR identified between the years 2005 and 2006, fully coincide with the time of the introduction of FDCAs in our country. Changes and patterns of RAMs prevalence are related to patterns of ARVs. exposure over time. Lower prevalence of all RAMS was observed in the Post-FDCAs period in our study. There are few studies about effectiveness of FDCAs on Resistances in HIV+ population. Miller et al. [24] found a decrease of RAMs prevalence since the commercial availability of FTC in a US population. The authors report a relationship between RAMS and ARVs. prescription changes, although the treatment history of patients was not available in their study.

We observed a downward trend in all class-resistance mutations, in agreement with other data from population studies, as in a Canadian study (British Columbia program) [25], whereas a Danish study (DHCS) [26] only found a significant decrease in NRTIs classresistance, but not in NNRTIs or PIs resistance. This could be explained by differences in the years the studies were performed. In the DHCS study the observations were conducted during the years 1999 to 2005 , whereas the Canadian study covered the years 1996 to 2008. MCDR also experienced a huge decrease, in concordance with a Portuguese study which analysed resistance data obtained from 2001 to 2006 [17]. As in the Canadian study, M184V/I was the most prevalent NRTI-related drug resistance mutation in the Catalan HIV+ population, followed by the most common TAMs related mutations, T215Y/F and M41L, and the prevalence of all these mutations decreased dramatically over time. Apart from the FDCAs, new NRTIs like Emtricitabine (FTC), with an increased use in recent years, could partially explain this observation. A random double-blind study in HIV naïve patients observed that the emergence of $\mathrm{M} 184 \mathrm{~V} / \mathrm{I}$ associated resistance was lower in patients treated with FTC than in those treated with 3TC [27].

The trend observed in the prevalence of K65R is consistent with the pattern of use of TDF and ddI combinations. This combination has been associated with a high early virological failure rate and with the occurrence of K65R mutation simultaneously [28].

K103N and V108I were the most prevalent NNRTI-related resistance mutations, and their prevalence experienced a 1.8 and 2 -fold decrease during the study period. L90M, M46I/L and V82A/F/T/S were the most prevalent PI-related resistance mutations and experienced a 2.5 and 3 -fold decrease overtime. This remarkable decrease could be explained by the emergence of more effective (Lopinavir and Atazanavir) and boosted PI therapy [18]. We observed a sharp decrease in PI- associated resistance mutations, which is related to the decrease in the use of first generation PIs and the increase in the use of second generation PIs. The fact that most of our patients were multithreaded may explain the decrease in the use of first generation PIs and NRTI and the increase in the use of new generation PIs.

Other authors support our findings. Bracciale et al. [16] found that more recent calendar year was predictor of more effective ARV treatment. Recently, a study in Western Europe, found an association between later calendar years and reduced probability of resistance [29]. However this is a retrospective study, not fully representative of the HIV+ population, and they did not investigate the relationship with prescription or exposure patterns.

Multiple drug resistance is an important obstacle to achieve optimal treatment in HIV patients, limiting ARVs. options and making it difficult to get an undetectable viral load [11]. In addition, triple class resistance has been described as an independent predictor of mortality in HIV patients [4]. It is important to determine which risk factors are associated with multiple drug resistance to prevent or guide health interventions.

In our study we found a higher risk of MCDR in male patients. Other authors have described higher numbers of RAMs in men [30] and male gender has been found as an independent risk factor for HIV resistance [31]. Gender differences in treatment adherence or variation in drug metabolism may explain these results.

Moreover, in our study we have found that sexual transmission group has a higher influence on the presence of triple class resistance than IDUs, in agreement with other studies 10. A high risk sexual behavior might partially explain this association [32]. Furthermore, the risk of MCDR was directly associated with the number of treatment failures and ARV-class exposure in agreement with other authors' results [10,16,31]. Age was an independent risk factor for MCDR, even after adjusting for the FDCAs period. In contrast with other studies $[10,31,33]$, we did not find association between VL or CD4 and the presence of MCDR, maybe due to the fact that most of the patients in our cohort were multithreaded and with an important virological failure.

Our study has some limitations to be considered. First, a potential bias in our study was that, although the time of appearance of emergence resistance mutations was unknown, we selected the first genotypic test available for each patient to assess the trends and changes after the introduction of FDCAs. For the multivariate analyses, the changing characteristics of the sampled population during the period of study were considered. Second, according to current clinical guidelines, only patients with VL $>1000$ copies $/ \mathrm{ml}$ were selected for analysis. However, patients with suspected virological failure and a $\mathrm{VL}<1.000$ copies $/ \mathrm{ml}$ who underwent genotypic resistance mutation tests were scarce. In addition, success rate of genotypic resistance test among these patients was low. Third, about $15 \%$ of patients were excluded from the study, although they fulfilled the inclusion criteria. However, no accurate 
Citation: Jaen A, Buira E, Giménez A, Pumarola T, Puig T, et al. (2015) Impact of Fixed-Dose Combinations of Antiretrovirals on Prevalence Trends of HIV Resistance: A 7 Year Follow-Up Study. J AIDS Clin Res 6: 416. doi:10.4172/2155-6113.1000416

treatment information was available on them and no relationship between resistance and treatment could be established. Finally, although different algorithms for the interpretation of genotypic resistance tests were used overtime [15], a strong correlation has been found between them (Jaen A, Guillot V, Gonzalez D, et al. Performance of the Spanish HIV Research Network (RIS) Resistance Interpretation Algorithm. [Poster, $\mathrm{n}^{\mathrm{o}}:$ 102]. Presented at: $7^{\text {th }}$ European HIV Drug Resistance Workshop, 2009, Stockholm).

In conclusion, an important risk reduction of genotypic resistances in HIV+ patients with virological failure has been observed after 2005 being at the same time of the introduction of FDCAs and new boosted PI therapy in Catalonia, independently of other risk and confounder factors. Our results seem to support the maintenance of FDCAs for the treatment of HIV infection.

Continued improvement of ARVs. and the increased availability of new drugs may contribute to the fact that emergence of new HIV drug resistances could be a rare event.

\section{Aknowledgments}

\section{Catalonia HIV Resistance Network (CHRN) and Collaborating Hospitals:}

E. Buira y A. Giménez de la Direcció General de Salut Pública Generalitat de Catalunya; A. Jaén, M. Xercavins y D. Dalmau del Hospital Universitari Mútua Terrassa; T. Pumarola, E. de Lazzari y J.M. Gatell del Hospital Clínic-Idibaps; T. Puig, L. Ruiz y B. Clotet del Hospital Universitari Germans Trias i Pujol; J. Niubó y D. Podzcamczer del Hospital de Bellvitge-Idibell; C.Fortuny del Hospital de San Joan de Déu; Hospital de la Santa Creu i Sant Pau, Hospital de la Vall d'Hebron, Hospital Materno-Infantil Vall d'Hebron, Hospital Creu Roja de Barcelona, Hospital del Mar, Hosp. Sagrat Cor-L'Aliança, Hospital Sant Jaume de Calella, Hospital de Mataró, Hospital General de Manresa, Centre Hospitalari i Cardiològic Manresa, Hospital del Parc Taulí de Sabadell, Hospital Gral. de Granollers, Hospital Gral. de Vic, Hospital de Terrassa, Hospital de Sant Bernabé, Fundació Privada Hospital de Mollet, Hospital Penitenciari, Hospital Residencia San Camil, Fundació San Igualada, Hospital Creu Roja de l'Hospitalet, Hospital Sant Llorens de Viladecans, Hospital Comarcal Alt Penedés, Hospital Arnau de Vilanova, Fundació Sant Hospital, Hospital Comarcal Mora d'Ebre, Hospital Sant Joan de Reus, Hospital Sant Pau i Santa Tecla, Pius Hospital de Valls, Hospital Joan XXIII, Hospital Verge de la Cinta, Hospital Comarcal Mora d'Ebre, Hospital Josep Trueta, Hospital Comarcal de La Selva, Hospital Provincial Santa Caterina, Hospital Figueres, Hospital Palamós, Hospital Sant Jaume d'Olot.

\section{References}

1. Palella FJ, Delaney KM, Moorman AC, Loveless MO, Fuhrer J, et al. (1998) Declining morbidity and mortality among patients with advanced human immunodeficiency virus infection. HIV Outpatient Study Investigators. N Engl J Med 338: 853-860.

2. Maggiolo F, Ripamonti D, Gregis G, Quinzan G, Callegaro A, et al. (2003) Oncea-day therapy for HIV infection: a controlled, randomized study in antiretroviralnaive HIV-1-infected patients. Antivir Ther 8: 339-346.

3. Pozniak AL, Gallant JE, DeJesus E, Arribas JR, Gazzard B, et al. (2006) Tenofovir disoproxil fumarate, emtricitabine, and efavirenz versus fixed-dose zidovudine/lamivudine and efavirenz in antiretroviral-naive patients: virologic, immunologic, and morphologic changes--a 96-week analysis. J Acquir Immune Defic Syndr 43:535-540.

4. Lohse N, Jørgensen LB, Kronborg G, Møller A, Kvinesdal B, et al. (2007) Genotypic drug resistance and long-term mortality in patients with triple-class antiretroviral drug failure. Antivir Ther 12: 909-917.

5. Di Giambenedetto S, Colafigli M, Pinnetti C, Bacarelli A, Cingolani A, et al (2008) Genotypic resistance profile and clinical progression of treatmentexperienced HIV type 1-infected patients with virological failure. AIDS Res Hum Retroviruses 24:149-154.

6. Cozzi-Lepri A, Phillips AN, Clotet B, Mocroft A, Ruiz L et al. (2008) Detection of HIV drug resistance during antiretroviral treatment and clinical progression in a large European cohort study. AIDS 22: 2187-2198.

7. Tural C, Ruiz L, Holtzer C, Schapiro J, Viciana P, et al. (2002) Clinical utility of HIV-1 genotyping and expert advice: the Havana trial. AIDS 16: 209-218.

8. Vandamme AM, Camacho RJ, Ceccherini-Silberstein F, de Luca A, Palmisano
L, et al. (2011) European HIV Drug Resistance Guidelines Panel. European recommendations for the clinical use of HIV drug resistance testing: 2011 update. AIDS Rev 13: 77-108

9. Panel on Antiretroviral Guidelines for Adults and Adolescents. Guidelines for the use of antiretroviral agents in HIV-1-infected adults and adolescents. Department of Health and Human Services

10. Di Giambenedetto S, Zazzi M, Corsi P, Gonnelli A, Di Pietro M, et al. (2009) Evolution and predictors of HIV type-1 drug resistance in patients failing combination antiretroviral therapy in Italy. Antivir Ther 14: 359-369.

11. Tozzi V, Zaccarelli M, Bonfigli S, Lorenzini P, Liuzzi G, et al. (2006) Drugclass-wide resistance to antiretrovirals in HIV-infected patients failing therapy: prevalence, risk factors and virological outcome. Antivir Ther 11: 553-560.

12. Costagliola D, Descamps D, Assoumou L, Morand-Joubert L, Marcelin AG, et al. (2007) Prevalence of HIV-1 drug resistance in treated patients: a French nationwide study. J Acquir Immune Defic Syndr 46: 12-18.

13. Daar ES, Richman DD (2005) Confronting the emergence of drug-resistant HIV type 1: impact of antiretroviral therapy on individual and population resistance. AIDS Res Hum Retroviruses 21: 343-357.

14. Shafer RW, Rhee SY, Bennett DE (2008) Consensus drug resistance mutations for epidemiological surveillance: basic principles and potential controversies. Antivir Ther 13 Suppl 2: 59-68.

15. de Mendoza C, Anta L, García F, Pérez-Elías MJ, Gutiérrez F, et al. (2009) HIV-1 genotypic drug resistance interpretation rules - 2009 Spanish guidelines. AIDS Rev 11: 39-51.

16. Bracciale L, Fanti I, Di Giambenedetto S, Colafigli M, Prosperi M, et al. (2009) Predictors of successful genotype-guided antiretroviral therapy in treatmentexperienced individuals over calendar years: a cohort study. J Clin Virol 46: 290-294.

17. Vercauteren J, Deforche K, Theys K, Debruyne M, Duque LM, et al. (2008) The incidence of multidrug and full class resistance in HIV-1 infected patients is decreasing over time (2001-2006) in Portugal. Retrovirology 5:12.

18. Dunn D, Geretti AM, Green H, Fearnhill E, Pozniak A, et al. (2008) UK Collaborative Group on HIV Drug Resistance; UK Collaborative HIV Cohort Study. Population trends in the prevalence and patterns of protease resistance related to exposure to unboosted and boosted protease inhibitors. Antivir Ther 13:771-777.

19. Llibre JM, Antela A, Arribas JR, Domingo P, Gatell JM, et al. (2010) Role of fixed-dose combinations of antiretrovirals in HIV-1 therapy. Enferm Infecc Microbiol Clin 28: 615-620.

20. Llibre JM, Arribas JR, Domingo P, Gatell JM, Lozano F, et al. (2011) Spanish Group for FDAC Evaluation. Clinical implications of fixed-dose coformulations of antiretrovirals on the outcome of HIV-1 therapy. AIDS 25: 1683-1690.

21. Gallego O, Ruíz L, Vallejo A, Clotet B, Leal M, et al. (2002) Rate of virological treatment failure and frequencies of drug resistance genotypes among human immunodeficiency virus-positive subjects on antiretroviral therapy in Spain. J Clin Microbiol 40: 3865-3866.

22. Gallego O, Ruiz L, Vallejo A, Ferrer E, Rubio A, et al. (2001) Changes in the rate of genotypic resistance to antiretroviral drugs in Spain. AIDS 15: 1894-1896.

23. Johnson VA, Brun-Vezinet F, Clotet B, Gunthard HF, Kuritzkes DR, et al. (2008) Update of the Drug Resistance Mutations in HIV-1. Top HIV Med 16:138-145.

24. Miller MD, Haddad M, Su C, Gibbs C, McColl DJ, et al. (2012) Trends in HIV1 reverse transcriptase resistance-associated mutations and antiretroviral prescription data from 2003-2010. Antiv Ther 17: 993-999.

25. Gill VS, Lima VD, Zhang W, Wynhoven B, Yip B, et al. (2010) Improved virological outcomes in British Columbia concomitant with decreasing incidence of HIV type 1 drug resistance detection. Clin Infect Dis 50: 98-105.

26. Audelin AM, Lohse N, Obel N, Gerstoft J, Jørgensen LB (2009) The incidence rate of HIV type-1 drug resistance in patients on antiretroviral therapy: a nationwide population-based Danish cohort study 1999-2005. Antivir Ther 14: 995-1000.

27. Modrzejewski KA, Herman RA (2004) Emtricitabine: a once-daily nucleoside reverse transcriptase inhibitor. Ann Pharmacother 38:1006-1014.

28. Podzamczer D, Ferrer E, Gatell JM, Niubo J, Dalmau D, et al. (2005) Early virological failure with a combination of tenofovir, didanosine and efavirenz. Antivir Ther 10:171-177. 
Citation: Jaen A, Buira E, Giménez A, Pumarola T, Puig T, et al. (2015) Impact of Fixed-Dose Combinations of Antiretrovirals on Prevalence Trends of HIV Resistance: A 7 Year Follow-Up Study. J AIDS Clin Res 6: 416. doi:10.4172/2155-6113.1000416

29. De Luca, Dunn D, Zazzi M, Camacho R, Torti C, et al. (2013) Declining Prevalence of HIV-1 Drug Resistance in Antiretroviral Treatment -exposed Individuals in Western Europe. J Infect Dis 207:1216-1220

30. Cubano LA, Sepúlveda-Torres Ldel C, Sosa G, Boukli N, Robles R, et al. (2008) Prevalence of drug resistance and associated mutations in HIV-positive Puerto Ricans: sex variations. Ethn Dis 18: S2-132-136.

31. Di Giambenedetto S, Bracciale L, Colafigli M, Cattani P, Pinnetti C, et al. (2007) Declining prevalence of HIV-1 drug resistance in treatment-failing patients: a clinical cohort study. Antivir Ther 12: 835-839.
32. Chin-Hong PV, Deeks SG, Liegler T, Hagos E, Krone MR, et al. (2005) High-risk sexual behavior in adults with genotypically proven antiretroviral-resistant HIV infection. J Acquir Immune Defic Syndr 40: 463-471.

33. Moltó J, Gutiérrez F, Mora A, Masiá Mdel M, Escolano C, et al. (2002) Factors associated with resistance to human immunodeficiency virus protease inhibitors. Med Clin Barc 118: 721-724. 